\title{
A Teoria do Pluralismo Jurídico e os Espaços Públicos Urbanos
}

\section{Lucas Pizzolatto Konzen ${ }^{1}$}

\begin{abstract}
Resumo: Este artigo reflete a respeito da utilidade da teoria do pluralismo jurídico para a compreensão de um tema do cotidiano das cidades: a regulação jurídica dos espaços públicos urbanos. Do ponto de vista descritivo, a teoria do pluralismo jurídico revela que padrões de exclusão podem ser constituídos porque os espaços públicos consistem em bens permeados por intrincados arranjos de propriedade, os quais são estabelecidos por meio de uma interlegalidade de normas tanto estatais quanto não estatais. Do ponto de vista prescritivo, o modelo do pluralismo jurídico comunitário-participativo oferece um referencial teórico adequado à construção de arranjos de propriedade nos espaços públicos que assegurem a efetivação do direito à cidade.
\end{abstract}

Palavras-chave: Pluralismo Jurídico. Espaço Público Urbano. Propriedade..

\begin{abstract}
This article reflects upon the utility of legal pluralism theory for understanding a topic that is part of city everyday life: the legal regulation of urban public spaces. From a descriptive standpoint, legal pluralism theory reveals that patterns of exclusion can be constituted because urban public spaces consist in valuables permeated by intricate property arrangements that are established by an interlegality of state and nonstate norms. From a prescriptive standpoint, the model of participatory and communitarian legal pluralism offers an adequate theoretical foundation for constructing property arrangements designed to assure the effectiveness of the right to the city.
\end{abstract}

Keywords: Legal Pluralism. Urban Public Space. Property.

\section{Introdução}

O paradigma sociojurídico, modelo de cientificidade emergente entre os membros do movimento direito e sociedade - e na sociologia do

1 Doutorando em Direito e Sociedade, Programa Internacional Renato Treves, Università degli Studi di Milano, Itália e Lunds Universitet, Suécia. Bolsista MIUR/ UNIMI. Mestre em Sociologia do Direito, Oñati International Institute for the Sociology of Law, Espanha. Mestre em Direito, Estado e Sociedade, Universidade Federal de Santa Catarina. Graduado em Ciências Jurídicas e Sociais, Universidade Federal do Rio Grande do Sul. Contato: lucas.pizzolatto@unimi.it. 
direito enquanto disciplina -, carrega consigo o potencial (e, por que não dizer, explicita a promessa) de minar a hegemonia da dogmática jurídica na ciência do direito. Entre os traços mais marcantes do novo paradigma, está a incorporação da teoria do pluralismo jurídico ${ }^{2}$ enquanto premissa (KONZEN, 2010). A comunidade científica sociojurídica parte da ideia de que o Estado não constitui a fonte única e exclusiva de todo o direito (WOLKMER, 2001, p. 183) e reconhece que "[...] tanto no mundo atual quanto historicamente o direito manifesta-se em uma variedade de formas e em uma variedade de níveis". (HOOKER, 1975, p. 1, tradução nossa).

A perspectiva pluralista no direito considera assim que não apenas as formas estatais de direito ("oficiais e formais") interessam à compreensão do fenômeno jurídico, mas também as formas "oficiais e informais", "não-oficiais e formais" e "não-oficiais e informais"3 de normatividade social (FRIEDMAN, 2005, p. 4). Assume-se que constitui uma experiência comum no dia-a-dia e uma realidade inevitável da vida social a coexistência de diferentes corpos de normas jurídicas no mesmo espaço social (MENSKI, 2006, p. 83), cada qual gerado e imposto por distintos campos sociais semiautônomos (MOORE, 1972, p. 721). Problematizar a juridicidade, portanto, exigiria contemplar suas múltiplas manifestações de modo integrado, já que as distintas ordens jurídicas superpõem-se, interpenetram-se, contradizem-se e misturam-se no pensamento e nas ações cotidianas. Isso ocorre porque a "vida jurídica é constituída por uma in-

\footnotetext{
2 O termo pluralismo jurídico parece ter sido utilizado pela primeira vez na literatura científica ao intitular a coleção de ensaios organizada por Gilissen (1971), popularizandose a partir de então. Em 1978, foi fundada a Commission on Legal Pluralism. A partir de 1981, um importante periódico científico sociojurídico dedicado ao tema assumiu esta denominação, o Journal of Legal Pluralism.

3 Apenas para ilustrar com exemplos essas categorias, atendo-se àqueles mencionados por Friedman (2005, p. 4): qualifica-se enquanto fonte "oficial e formal", por exemplo, uma lei promulgada em uma nação moderna; como "oficial e informal", o comportamento de um fiscal de trânsito que, diante de uma infração, usa de discricionariedade e deixa de aplicar uma multa por considerar razoável a justificativa do infrator, sem deixar de lhe aplicar um sermão; como "não-oficial e formal", o código de uma universidade que prevê uma sanção disciplinar ao estudante que frauda uma prova; e como "não-oficial e informal", os pais que estabelecem e impõem regras aos filhos sobre como estes devem se comportar.
} 
tersecção de diferentes ordens jurídicas, isto é, pela interlegalidade." (SANTOS, 1995, p. 473, tradução nossa).

Todavia, embora a discussão abstrata a respeito da teoria do pluralismo jurídico venha ganhando espaço na academia nas últimas décadas, os avanços que foram alcançados no que se refere a sua aplicação à compreensão dos problemas concretos da vida cotidiana são ainda escassos. Por isso,

[...] atenção muito maior deve ser conferida à pesquisa empírica e à compreensão teórica das muitas variações que se pode encontrar nas constelações de pluralismo jurídico e às formas pelas quais essas diferentes constelações influenciam concretamente as condições sociais, políticas e econômicas do viver das pessoas envolvidas (BENDA-BECKMANN, 2002, p. 74, tradução nossa).

Tendo isso em mente, este artigo busca especular a respeito da utilidade da perspectiva pluralista do direito para a compreensão de um tema do cotidiano das cidades: a regulação jurídica dos espaços públicos urbanos. Através do conceito de espaços públicos urbanos procura-se abranger as ruas, praças, parques, praias e outros lugares materiais e concretos existentes nas cidades constituídos por relações sociais que tendem a potencialmente encorajar o encontro espacial das diferenças. Com fundamento em recentes construções teóricas de autores que são referências na discussão contemporânea do pluralismo jurídico, apontam-se duas formas distintas pelas quais se poderia, em tese, acrescentar elementos considerados importantes à evolução dos rumos dos debates sobre o assunto.

Cabe fazer a ressalva, porém, de que as proposições que seguem são eminentemente teórico-especulativas, carentes pelo momento da devida comprovação empírica de sua capacidade explanatória. Constituem, em suma, apostas teóricas, cujo ulterior desenvolvimento empírico faz-se imprescindível. 


\section{Espaços Públicos e Arranjos de Propriedade}

A primeira forma pela qual a teoria do pluralismo jurídico poderia contribuir à compreensão da dimensão jurídica da produção dos espaços públicos urbanos é do ponto de vista descritivo. Sugere-se que a noção de arranjos de propriedade (BENDA-BECKMANN, F.; BENDA-BECKMANN, K.; WIBER, 2006) - forjada sob a perspectiva pluralista do direito - oferece um profícuo esquema teórico para elucidar a regulação jurídica dos espaços públicos. A hipótese subjacente a essa noção seria a de que os padrões de exclusão podem ser constituídos porque os espaços públicos urbanos não são espaços fora do direito ou não afetados por relações de propriedade. Consistem, ao contrário, em bens permeados por intrincados arranjos de propriedade, os quais são estabelecidos por meio de uma interlegalidade de normas jurídicas tanto estatais quanto não estatais. Por conta disso, entender como os padrões de exclusão funcionam exitosamente na vida cotidiana exige desembrulhar, em relação a cada um dos espaços públicos de uma cidade em específico, o respectivo pacote de direitos e deveres disfarçado pelo conceito dogmático de bem de uso comum do povo.

$\mathrm{Na}$ visão de F. Benda-Beckmann, K. Benda-Beckmann e Wiber (2006, p. 1-15), a categoria propriedade é multifuncional e há muito está ao centro das principais lutas intelectuais, econômicas, políticas e sociais que marcaram a história. Ocorre que a propriedade não se resume a um tipo específico de direito ou relação como a propriedade privada. É um termo abrangente que abarca uma ampla variedade de arranjos, em diferentes sociedades e ao longo de distintos períodos históricos, incluindo tanto o uso legal quanto o ilegal de recursos. Em um sentido mais geral, a propriedade " $[$...] faz referência às maneiras pelas quais se confere forma e significado às relações entre os membros de uma sociedade no que diz respeito a certos bens [...]" (2006, p. 14, tradução nossa), “[...] concerne à organização e legitimação de direitos e obrigações a respeito de bens a que se atribui valor" (p. 2, tradução nossa). Por isso, os arranjos de propriedade são o foco de conflitos e renegociações em todos os níveis de organização da sociedade - família, classe, Estado -, desempenhando um papel-chave nos processos de mudança social. 
No entanto, os referidos autores fazem notar que, por conta das justificáveis e intensas disputas ideológicas em torno da questão acerca de como devem ser as relações de propriedade ideais, insuficiente atenção vem sendo prestada quanto à descrição acurada da maneira que estas operam concretamente na realidade da vida cotidiana. Em síntese, inexiste à disposição, atualmente, qualquer esquema rigoroso que permita analisar descritivamente como os arranjos de propriedade realmente funcionam. Diante de tal diagnóstico, os autores buscam resgatar o potencial explicativo da metáfora da propriedade como um pacote de direitos. A propriedade consistiria, assim, em um pacote de direitos que precisa ser desembrulhado sem que neste processo se deixe de capturar as complexidades envolvidas. Nessa esteira, seria indispensável resistir à tendência de interpretar quaisquer arranjos de propriedade reduzindo-os a uma das "quatro grandes categorias" supostamente universais: propriedade privada, propriedade condominial, propriedade estatal e propriedade de livre acesso. A metáfora do pacote de direitos é aplicável não só ao desdobramento de cada uma dessas grandes categorias, mas também à caracterização dos direitos específicos atrelados a um determinado bem ou aos direitos dos quais é titular uma determinada unidade social (BENDA-BECKMANN, F.; BENDA-BECKMANN, K.; WIBER, 2006, p. 2-4, 15).

A leitura do problema da propriedade por parte de F. Benda-Beckmann, K. Benda-Beckmann e Wiber em diversos pontos é coincidente com a de Azuela (1999), que já sinalizava a pertinência da noção de arranjos de propriedade para discutir os espaços urbanos. $\mathrm{O}$ autor sustenta que esses arranjos são um "aspecto constitutivo das relações sociais de propriedade. Esta não pode existir como relação social se não existe como relação jurídica" (AZUELA, 1999, p. 203, tradução nossa). Azuela igualmente problematiza a definição do conteúdo jurídico da propriedade com base nas quatro grandes categorias. Aponta, por exemplo, a inadequação à realidade atual da noção de propriedade privada de conteúdo absoluto que é tradicional ao direito civil, uma vez que hoje se aplicam conjuntos normativos distintos a tipos diversos de propriedade (AZUELA, 1999, p. 203). Azuela lembra, por outro lado, que há uma distância entre o discurso jurídico oficial e o conteúdo efetivo de um arranjo de propriedade, já que "os textos (de leis, regulamentos, sentenças) através dos quais se 
expressam as normas que compõem tal regime podem variar enormemente sem que varie o conteúdo de tais normas". (AZUELA, 1999, p. 203, tradução nossa) ${ }^{4}$.

Azuela avança na caracterização dos arranjos de propriedade ao identificar três elementos que são básicos a este tipo de relação social: a) os sujeitos de direitos; b) os objetos passíveis de se tornarem propriedade; e c) os direitos quanto aos quais é possível reivindicar a proteção estatal. No que concerne aos processos que ocasionam a mudança desses elementos, o autor observa que o direito influi na formação das relações de propriedade basicamente de três formas: a) na constituição dos sujeitos sociais; b) na delimitação estatal dos interesses de tais sujeitos; e c) na generalização dessa delimitação (AZUELA, 1999, p. 203-204).

De acordo com Azuela (1999, p. 210, tradução nossa), “[...] a constituição dos sujeitos de direito [constitui] condição para o desenvolvimento de certas práticas sociais." Se, por um lado, os distintos atores sociais sociologicamente inserem-se em classes e grupos sociais, por outro, de um ponto de vista jurídico, atuam muitas vezes não individualmente enquanto seres humanos, mas coletivamente por intermédio de corporações jurídicas específicas - uma empresa, uma família, uma associação de moradores. Essas corporações existem por conta de normas jurídicas, são meras ficções que permitem certas práticas dos verdadeiros sujeitos que são sempre as pessoas (AZUELA, 199, p. 210-211). Muitas vezes são estes sujeitos de direito que possuem a prerrogativa, atribuída pela ordem jurídica oficial, de invocar a proteção estatal de certos interesses, e não as pessoas individualmente consideradas. "O limite (a medida) desta proteção está dado pelo conteúdo normativo do regime de propriedade" (p. 211, tradução nossa). No que concerne a este último aspecto, "o papel

\footnotetext{
4 "Longe de ser uma versão neutra e unívoca das normas que contêm, tais direitos estão marcados pela ideologia e pela cultura político-jurídica de seus autores (legisladores, funcionários, juízes, tratadistas etc.), de modo que para conhecer o conteúdo normativo de uma instituição, sempre é necessário fazer uma interpretação de tais textos. É por isso que a investigação sociológica que pretende compreender a função social do regime jurídico da propriedade enquanto conjunto de normas não pode deixar de fazer este trabalho interpretativo sem correr o risco de aceitar como válida a versão que o discurso jurídico oferece acerca da ordem jurídica" (AZUELA, 1999, p. 203, tradução nossa).
} 
do direito [...] não consiste unicamente em definir a medida da proteção estatal, mais importante ainda é que a norma jurídica generaliza essa medida ao conjunto de situações concretas que cabem sob a sua definição." (p. 212, tradução nossa). Ou seja, "o direito tende a generalizar, a igualar, o que em outro sentido é individual e diverso [...]", desencadeando uma tensão entre a generalidade da norma e cada uma das relações sociais reguladas (p. 212, tradução nossa).

O esquema analítico proposto por F. Benda-Beckmann, K. Benda-Beckmann e Wiber (2006) para o propósito de desembrulhar os arranjos de propriedade, embora não dialogue com as reflexões de Azuela, incorpora-lhes em uma estrutura teórica mais sofisticada e dotada de maior clareza conceitual. Os autores referem que, nas sociedades modernas, os arranjos de propriedade costumam ser altamente formalizados no que se refere ao estrato jurídico-institucional. O ordenamento jurídico estatal é construído em torno de algumas poucas categorias-mestre, úteis para classificar problemas e resolver disputas, justamente em função de generalizarem arranjos de propriedade em si totalmente abstratos a um conjunto diversificado de situações fáticas concretas. Essas categorias gerais, como é o caso da propriedade privada ou do bem de uso comum do povo, especificam unidades sociais, objetos de propriedade e direitos e responsabilidades que estão atrelados. Não obstante, elas descuidam completamente de aspectos inerentes aos arranjos de propriedade na vida real que se verificam em dois outros estratos distintos: o estrato das relações concretas e o estrato ideológico.

Nesse sentido, dois eixos articulados são contemplados pelo modelo abrangente e pluralista elaborado por F. Benda-Beckmann, K. Benda-Beckmann e Wiber (2006, p. 15-16) para analisar os arranjos de propriedade: a) os elementos das relações de propriedade; e b) os estratos de organização social. O primeiro eixo envolve três elementos centrais das relações de propriedade: a.1) as unidades sociais; a.2) os objetos de propriedade; e a.3) os direitos e responsabilidades. O segundo eixo é composto dos três estratos de organização social concernentes à propriedade: b.1) o estrato jurídico-institucional; b.2) o estrato das relações concretas; e b.3) o estrato ideológico (Quadro 1). O que a propriedade representa em cada um desses estratos pode variar significativamente, não sendo possível reduzir 
o que a propriedade significa em um estrato ao que ela constitui em outro. Cada estrato de um arranjo de propriedade pode mudar em diferentes ritmos e por distintas razões, mas todos estão inter-relacionados. Interessa, pois, compreender detalhadamente essas inter-relações entre os estratos e de que forma as transformações ocorrem em cada um deles.

\begin{tabular}{|l|l|}
\hline \multicolumn{2}{|c|}{ ARRANJOS DE PROPRIEDADE: } \\
\hline (a) Elementos da propriedade: & (b) Estratos de organização social: \\
\hline $\begin{array}{l}\text { (a.1) unidades sociais } \\
\text { Os titulares de direitos e obrigações em rela- } \\
\text { ção a bens, por exemplo, o Estado, o indiví- } \\
\text { duo, o grupo, a linhagem, a corporação. }\end{array}$ & $\begin{array}{l}\text { (b.1) estrato jurídico-institucional } \\
\text { em outros termos, aquelas legalmente forma- } \\
\text { lizadas pelo direito estatal ou ainda por ordens } \\
\text { jurídicas competitivas quando for o caso (fre- } \\
\text { quentemente existem poucas categorias-mestre } \\
\text { com um conjunto de direitos específicos a elas } \\
\text { atrelados). }\end{array}$ \\
\hline $\begin{array}{l}\text { (a.2) objetos de propriedade } \\
\text { Os bens materiais e imateriais aos quais se } \\
\text { atribui valor. }\end{array}$ & $\begin{array}{l}\text { (b.2) estrato das relações concretas } \\
\text { As práticas correntes na vida cotidiana, as } \\
\text { quais muitas vezes revelam arranjos intrinca- } \\
\text { dos. }\end{array}$ \\
\hline $\begin{array}{l}\text { (a.3) direitos e responsabilidades } \\
\text { O conjunto de relações estabelecidas entre as } \\
\text { unidades sociais acerca dos objetos de proprie- } \\
\text { dade. }\end{array}$ & $\begin{array}{l}\text { (b.3) estrato ideológico } \\
\text { As noções culturais gerais, filosofias e ideo- } \\
\text { logias, como, por exemplo, o comunismo, o } \\
\text { capitalismo, o fetichismo da propriedade pri- } \\
\text { vada, a social-democracia etc., que justificam } \\
\text { os arranjos de propriedade existentes ou dese- } \\
\text { jáveis. }\end{array}$ \\
\hline
\end{tabular}

Quadro 1: O estrato ideológico

Fonte: Adaptado de F. Benda-Beckmann, K. Benda-Beckmann e Wiber (2006)

Embora esteja além do escopo deste trabalho demonstrar a pertinência empírica desse esquema analítico à compreensão do funcionamento dos arranjos de propriedade, soa relevante ao menos ilustrar com uma situação hipotética como se poderia aplicá-lo ao entendimento dos conflitos sociais em torno dos espaços públicos. Considere-se, por exemplo, 
a praça " $X$ ", situada no centro de uma cidade brasileira chamada "Y". Observando-se a praça na data 01.01.01, percebe-se uma multiplicidade de usos, presenças e discursos por parte dos mais distintos grupos sociais, tais como o dos vendedores ambulantes. Pressionada pela "Associação de Empresários do Turismo Local", a prefeitura da cidade Y passa a cogitar a instalação na praça $X$ de um monumento de um escultor famoso, que pudesse transformá-la em atração turística. O Prefeito solicita aos advogados do município que elaborem um parecer acerca das normas jurídicas que regulamentam a área ocupada pela praça X. Os advogados, citando a legislação municipal e federal, a jurisprudência e um famoso doutrinador do direito urbanístico, elaboram o parecer, de indiscutível qualidade dogmática. Em síntese, manifestam-se no sentido de que a área da praça $\mathrm{X}$ integra o domínio público municipal e consiste em um bem de uso comum do povo. Acrescentam que a propriedade urbana deve cumprir sua função social, estabelecida pelo plano diretor, que no caso da cidade $\mathrm{Y}$ confirma a afetação de praça da área indicada, cujo uso normal deve ser a atividade de recreação. A construção do monumento se coaduna com a afetação da praça e, ademais, é prerrogativa do poder executivo municipal decidir como organizá-la fisicamente. Os procuradores aproveitam para lembrar que cabe à prefeitura exercer o poder de polícia administrativa, regulamentando e fiscalizando os usos da praça a fim de que se atenham a sua destinação normal.

Em 02.02.02, o Prefeito inaugura o monumento. Na ocasião, em clima festivo, comunica que entrou em vigor uma nova lei municipal, proibindo o comércio ambulante na praça $\mathrm{X}$ e estabelecendo multas para os infratores, pois, nas suas palavras, "é preciso garantir que os turistas que visitam nossa cidade não sejam incomodados". Os vendedores ambulantes, ao perceberem que a prefeitura só dispõe de um único agente de fiscalização para aplicar as multas, decidem resistir e continuar suas atividades. Nas poucas oportunidades em que o fiscal aparece, os ambulantes afastam-se da praça, retornando em seguida, de forma que raras vezes são aplicadas multas. Decidem, ademais, fundar a "Associação dos Vendedores Ambulantes da Praça X", cadastrando seus membros e apresentando à prefeitura um projeto de lei que regulamenta a atividade na praça; passam também a promover protestos na praça exigindo da câmara de vere- 
adores que aprove o projeto. A Associação dos Empresários do Turismo Local reage. Pública anúncios pagos nos jornais da cidade, que em contrapartida mobilizam seus colunistas e repórteres para denunciar as "acintosas ilegalidades" praticadas pelos vendedores ambulantes na praça X. Ademais, ela acorda com a prefeitura a "adoção" da praça, o que inclui a disponibilização dos serviços de uma empresa de segurança privada para "proteger o monumento"; a mesma empresa de segurança é contratada para "proteger o comércio formal", no que se subentende estar incluída a tarefa de intimidar os vendedores ambulantes.

O Prefeito, entretanto, é derrotado nas eleições e seu sucessor, mais simpático à causa dos vendedores ambulantes, logra em 03.03.03 aprovar junto à Câmara de Vereadores uma alteração na lei municipal sobre o comércio ambulante na praça $X$. De acordo com a nova redação, ficam autorizados a exercer essa atividade naquele local os vendedores cadastrados pela Associação dos Vendedores Ambulantes da Praça X, mediante o pagamento de uma taxa anual à prefeitura e desde que respeitado um limite máximo preestabelecido quanto ao número de licenças a serem concedidas. Surgem, no entanto, problemas com as práticas jurídicas internas da Associação dos Vendedores Ambulantes da Praça X. Nem todos os vendedores ambulantes em atividade conseguem se cadastrar e questionam-se os critérios de escolha daqueles a quem serão concedidas as licenças. Uma das vendedoras cadastradas vem a falecer e seu filho de 17 anos exige que lhe seja transmitido o "direito de licença", já que do contrário sua família ficaria sem renda. A Associação de Empresários do Turismo Local, por outro lado, insurge-se contra as modificações na lei e ingressa com uma ação judicial alegando que a inovação legislativa vai de encontro à afetação da área para o lazer e, portanto, fere o plano diretor; argumenta, ainda que o poder de polícia de que dispõe a municipalidade é indelegável mesmo que em parte à Associação dos Vendedores Ambulantes da Praça X.

Seria possível continuar detalhando a situação hipotética exposta, mas já foi dito o suficiente para conduzir um resumido ensaio de aplicação do esquema analítico proposto por F. Benda-Beckmann, K. Benda-Beckmann e Wiber. Primeiro, cabe fazê-lo em relação aos elementos da propriedade. O objeto de propriedade a que se atribui valor, no caso, não 
é outro senão a praça $X$ enquanto espaço público. As unidades sociais titulares de direitos e obrigações que aparecem ao longo da narrativa são a Prefeitura Municipal, a Associação dos Vendedores Ambulantes da Praça X, a Associação de Empresários do Turismo Local, a empresa de segurança privada, os agentes de fiscalização, os turistas, os vendedores ambulantes individualmente considerados e seus familiares. $\mathrm{O}$ leque de direitos e responsabilidades envolvidos tampouco se mostra menos diversificado: o direito de não ser incomodado ao contemplar um monumento em uma praça, a responsabilidade de proteger um monumento, a responsabilidade de fiscalizar e multar, o direito de adotar uma praça, a responsabilidade de cadastrar vendedores ambulantes, o direito à transmissão da licença, o direito de exercer o poder de polícia, o direito de comerciar informalmente, o direito de decidir sobre a validade de uma lei e assim por diante.

Segundo, é necessário examinar os estratos de organização social. No que se refere ao estrato jurídico-institucional, é possível identificar uma variedade de enunciados normativos conectando os elementos da propriedade. Por exemplo, aqueles formulados pelos advogados municipais em seu parecer: “[...] a Prefeitura Municipal, exercendo seu poder de polícia, pode decidir proibir e sancionar com multas certos usos da praça [...]"; "a Prefeitura Municipal, sendo seu direito decidir acerca da organização física da praça X, pode instalar um monumento no local.”. Também o projeto de lei dos vendedores ambulantes regulamentando a atividade na praça contém esse tipo de enunciado: "a Prefeitura Municipal pode delegar atividades inerentes ao poder de polícia de que dispõe à Associação dos Vendedores Ambulantes da Praça X". Neste ponto, fosse exclusivamente dogmática a análise, nada mais restaria a examinar. De acordo com o esquema analítico dos arranjos de propriedade, entretanto, importa também capturar o estrato das relações concretas e o estrato ideológico.

A juridicidade de um enunciado normativo do tipo "o turista não deve ser incomodado ao contemplar um monumento na praça X" assume significado, por exemplo, no estrato ideológico e não no estrato jurídico-institucional. $\mathrm{O}$ mesmo se pode afirmar em relação a enunciados como "é garantido a todos o direito de comerciar nas praças da cidade", "a função social da praça X é a recreação" ou "comerciar informalmente na praça X constitui uma acintosa ilegalidade”. Esses enunciados, ainda 
que eventualmente estejam incorporados aos textos legais oficiais, constituem formas de manifestação da consciência jurídica emanadas de certos grupos sociais. São maneiras particulares de idealizar o que é e o que não é direito que podem se reproduzir e se tornar socialmente hegemônicas ao ponto de se transformarem em algo fora de disputa, mas também podem permanecer perifericamente no imaginário de grupos sociais não hegemônicos e em contradição com os discursos jurídicos oficiais.

De outra parte, certos enunciados normativos escapam às relações categóricas de propriedade ao revelarem sua juridicidade no que diz respeito ao estrato das relações concretas, como ao se constatar que "se pode comerciar na praça X quando os agentes de fiscalização não se fizerem presentes", que "se sanciona com multa a atividade de comércio informal na praça X somente quando flagrada pela fiscalização", que "se autoriza os agentes de empresas privadas de segurança a coibir a ação dos vendedores ambulantes" ou ainda que "a Associação dos Vendedores Ambulantes da Praça X não credencia vendedores com idade inferior a 18 anos". No uso cotidiano do espaço público, as formas concretas de juridicidade assumem papel por vezes muito mais relevante que aquelas do estrato jurídico-institucional, embora com estas se relacionem.

\section{Espaços Públicos e Pluralismo Jurídico Comunitário-Partici- pativo}

Descrições sobre como o pluralismo jurídico funciona na realidade da vida cotidiana, entretanto, são insuficientes para superar o paradigma vigente na ciência do direito. Ultrapassar afirmações sobre o "ser" do pluralismo jurídico é uma tarefa que exige de seus defensores a proposição de enunciados também voltados ao seu "dever-ser". Por isso, identificar e analisar as diversas formas de pluralidade jurídica que se verificam nos arranjos de propriedade dos espaços públicos urbanos é uma meta válida se encarada como passo inicial. Dar o passo seguinte, o de avançar na construção de arranjos de propriedade embasados em modelos, valores e práticas pluralistas, é essencial. A formulação de prescrições a partir da teoria do pluralismo jurídico revela-se uma tarefa necessária e inolvidá- 
vel, porque não se pode renunciar a juízos de valor na ciência, sobretudo quanto ao direito. Portanto, a segunda forma pela qual a teoria do pluralismo jurídico poderia contribuir à compreensão da dimensão jurídica da produção dos espaços públicos urbanos é do ponto de vista prescritivo.

Nessa direção, esta seção retoma a rica discussão acadêmica sobre o pluralismo jurídico no Brasil, que teve início justamente com uma pesquisa sociojurídica realizada por Santos (1977, 1980, 1988a, 1988b, 1995) a respeito de um dos mais emblemáticos espaços das cidades latino-americanas: a favela. Busca-se mostrar, ainda que brevemente, como a reflexão teórica do autor em torno da juridicidade da favela e do papel do direito na produção do espaço urbano capitalista evoluiu de uma análise descritiva do funcionamento das práticas jurídicas pluralistas à formulação de uma teoria prescritiva sobre o que poderia vir a ser o direito pós-moderno. Na sequência, intenta-se articular as contribuições de Santos com o "pluralismo jurídico comunitário-participativo" - proposta de cunho igualmente prescritivo elaborada por Wolkmer (2001) - para, ao final, aplicar-se esta teoria à elucidação de um debate contemporâneo sobre os espaços públicos urbanos, travado no contexto estadunidense, entre Mitchell e Ellickson. Sugere-se que o pluralismo jurídico comunitário-participativo distingue-se de outros referenciais teóricos pluralistas concorrentes, seja pela sua capacidade de impulsionar as lutas dos movimentos sociais urbanos, seja pela sua utilidade para delinear arranjos de propriedade do espaço público que tendam a assegurar a efetivação do direito à cidade.

Nos anos 1970, Santos investigou o pluralismo jurídico na Favela do Jacarezinho, no Rio de Janeiro ${ }^{5}$. Fruto das lutas sociais por melhores condições habitacionais, a favela configurava um espaço urbano ilegal, no sentido de que a ocupação e a urbanização ocorriam à revelia ou em

5 Neste estudo empírico o autor partiu do pressuposto de que, nas sociedades capitalistas, “o sistema jurídico estatal é em geral um instrumento de dominação de classe tanto no nível das relações de produção, como na fábrica, quanto no nível das relações de reprodução, como na habitação" (1977, p. 5, tradução nossa). Tal pressuposto retratava uma interpretação então corrente da obra de Marx no que se referia a sua visão a respeito do direito estatal, segundo a qual este se resumia a um instrumento de dominação de classe. 
franca violação das disposições do direito urbanístico estatal. No dizer de Santos (1980, p. 88), "a favela é um espaço territorial, cuja relativa autonomia decorre, entre outros fatores, da ilegalidade coletiva da habitação à luz do direito oficial brasileiro". A condição de ilegalidade coletiva tornava estruturalmente inacessível o sistema jurídico oficial (essencialmente, a polícia e os tribunais como suas agências) para os moradores da Favela do Jacarezinho no que se referia à regulação dos conflitos espaciais internos à comunidade 6 . Em especial, esses conflitos que surgiam entre os moradores diziam respeito à posse da terra e aos direitos sobre as casas e os barracos que nela iam sendo construídos. Era necessário, a despeito disso, prevenir e solucionar tais situações de conflito, do contrário elas poderiam acabar prejudicando a própria luta social coletiva da comunidade. Diante dessa exigência, a comunidade da favela desenvolvera mecanismos normativos e órgãos decisórios próprios - seja conflitantes ou inspirados na legalidade estatal - articulados em torno da associação de moradores, capazes de assegurar um mínimo de coesão social interna (SANTOS, 1980, 1988a), ao que Santos apelidou de "direito de Pasárgada"7.

Para Santos, tratava-se de um exemplo de "direito paralelo usado pelas classes urbanas oprimidas para sobreviver em (e adaptar-se a) uma rígida sociedade de classes" (1977, p. 9, tradução nossa). Ademais, segundo o autor, "porque se centra à volta de uma organização eleita pela comunidade, o direito de Pasárgada representa [...] a alternativa de uma administração democrática da justiça" (SANTOS, 1988a, p. 99). Ainda que o foco central de Santos estivesse direcionado à retórica jurídica, seu pioneiro estudo acabou por influenciar diversos outros trabalhos sobre o pluralismo jurídico em assentamentos urbanos informais. O relativo oti-

6 Conscientes da ilegalidade coletiva da favela perante o direito expresso nos códigos aplicados pelos juízes, os moradores de Jacarezinho sabiam que "recorrer aos tribunais para resolver conflitos sobre terras e habitações não só era inútil como perigoso" (SANTOS, 1980, p. 92), já que, nos termos do direito estatal, todos os moradores corriam o permanente risco de serem despejados e terem suas casas demolidas pelo Estado.

7 Temendo que a divulgação de certas informações prejudicasse politicamente os líderes da comunidade onde desenvolvera a pesquisa participante, por vários anos Santos procurou ocultar dados sobre a realidade do Jacarezinho. Omitiu inclusive a própria identidade da favela, utilizando-se do nome fictício de Pasárgada para se referir a ela. (SANTOS, 1988b). 
mismo inicial de Santos para com as possibilidades do direito de Pasárgada - para ele, o direito dos oprimidos, contraposto ao direito estatal dos opressores - foi, todavia, rejeitado por outros pesquisadores, que perceberam certo romantismo maniqueísta em tal contraposição. Estudos como o de Junqueira e Rodrigues (1988) mostraram que, no espaço das favelas, também emergem práticas informais de juridicidade paralela opressoras, como aquelas vinculadas ao narcotráfico organizado, que às vezes estão em conflito e às vezes associadas ao direito oficial estatal ou à juridicidade manejada por associações de moradores.

As pesquisas de Santos ao longo da década de 1980 suscitaram elementos adicionais para a análise sociojurídica do fenômeno urbano. Durante este período, o autor promoveu um incipiente diálogo entre a sociologia do direito e o emergente paradigma socioespacial em sociologia urbana. Inserindo-se em um contexto político de mobilização pela redemocratização na América Latina, Santos investigou as lutas urbanas na cidade de Recife, enfatizando uma nova problemática: o uso alternativo do direito estatal pelos moradores de assentamentos irregulares como forma de alcançar a regularização fundiária da ocupação e a efetivação do direito à moradia. $\mathrm{O}$ direito oficial passa a aparecer na obra do autor não se restringindo a um componente da ordem espacial hegemônica. Assume um caráter muito mais ambíguo, na condição de elemento que pode ser potencialmente mobilizado também por atores contra-hegemônicos a fim de desafiar essa mesma ordem (SANTOS, 1982, 1983).

Posteriormente, nos anos 1990, Santos apresentou a por ele denominada "cartografia simbólica do direito". Trata-se de uma sofisticada construção teórica relativa ao pluralismo jurídico calcada em elementos empíricos coletados pelo autor em suas experiências anteriores de pesquisa. De acordo com Santos, o direito moderno está baseado na premissa de que o direito opera em uma única escala, que é a escala do Estado. Todavia, a realidade mostra uma paisagem jurídica muito diferente disso. Por toda parte há uma pluralidade de ordens jurídicas, assim como uma pluralidade de formas de poder e conhecimento. Seis principais formas de direito são distinguidas por Santos: o direito doméstico, o direito da produção, o direito do mercado, o direito da comunidade, o direito territorial (ou direito estatal) e o direito sistêmico; cada uma delas está conecta- 
da a modalidades específicas de poder e conhecimento (SANTOS, 1995, p. 424-438). Tal cartografia simbólica do direito não compreende o pluralismo jurídico como diferentes ordens jurídicas coexistindo separadamente no mesmo espaço social. Ao contrário, ela percebe essas ordens jurídicas como superpostas, interpenetradas e misturadas em nossas mentes e ações, o que significa que o conceito de interlegalidade é chave em uma concepção pós-moderna do direito (SANTOS, 1995, p. 473). Isso não significa, porém, que o direito estatal irá perder a sua centralidade, precisamente porque o poder estatal e o conhecimento científico ainda são hegemônicos nas sociedades contemporâneas (SANTOS, 1995, p. 404). Mas o desafio pós-moderno, na visão do autor, é também desenvolver estratégias emancipatórias de luta social que alcancem as demais formas de direito, poder e conhecimento.

De fato, é uma posição teórica um tanto perigosa pressupor legítima qualquer tipo de regulação normativa apenas porque consiste em uma manifestação de pluralidade jurídica, ou ainda porque emana de grupos sociais oprimidos. Ao mesmo tempo, desconfiar excessivamente da legitimidade do direito estatal implica desconhecer que, ao longo da trajetória da modernidade, o Estado consagrou-se enquanto a principal esfera de luta democrática por mudanças socioeconômicas em prol dos oprimidos. O que resta claro da análise de Santos para a discussão aqui proposta concernente aos arranjos de propriedade em relação aos espaços públicos urbanos é que transformá-los exige a reinvenção da juridicidade de distintas esferas, entre elas a do Estado, e que cada uma dessas esferas de regulação comporta formas distintas de luta social que interagem com as demais, afetando-lhes reflexivamente. Nas palavras de Santos,

[...] uma mera alteração do direito estatal pode não alterar grande coisa se as outras ordens jurídicas se mantiverem e conseguirem restabelecer as suas articulações com o direito estatal noutros moldes. Além disso, o reconhecimento das constelações de direitos equivale a reconhecer que as práticas e as lutas emancipatórias têm também de se articular em rede e de se constelar se quiserem ser bem sucedidas. Caso contrário, uma luta isolada contra uma dada forma de regulação pode, involuntariamente, reforçar outra forma de regulação (2001, p. 303). 
Qualquer discussão referente ao pluralismo jurídico não pode, portanto, renunciar a juízos de valor, seja no que se refere às práticas na esfera estatal, seja quanto à esfera doméstica ou da comunidade, por exemplo. Sem orientações normativo-valorativas, fica difícil distinguir as formas opressivas de pluralidade jurídica daquelas emancipatórias. Nesse sentido, alguns acadêmicos sociojurídicos vêm tentando erigir modelos teóricos capazes de fornecer tais prescrições, aproximando a sociologia do direito da filosofia do direito. Entre estes, merece ser destacado o modelo de "pluralismo jurídico comunitário-participativo" apresentado por Wolkmer (2001). Por um lado, para o autor,

[...] nem toda a manifestação legal não-estatal ou nem todo "direito" aí produzido pode ser justo, válido e ético, pois um corpo social intermediário ou grupo dirigente qualquer pode criar regras perversas, objetivando atender interesses contrários à comunidade, expressando diretamente intentos de minorias identificadas com o poder, a dominação, a exploração e o egoísmo. Nesse caso, existem direitos particulares produzidos por uma pluralidade de grupos sociais que não são justificáveis e legítimos [...] A ausência de valores mínimos e universais relacionados à eticidade e à justiça esvaziam a legitimidade desses "direitos". (WOLKMER, 2001, p. 324).

Por outro lado, Wolkmer discute o papel desempenhado pela pluralidade jurídica no processo de construção social dos direitos humanos. Ele argumenta que movimentos sociais emancipatórios atuam como fonte de legitimidade dos direitos. Em suas lutas sociais, eles concebem representações jurídicas contra-hegemônicas emergentes de necessidades coletivas insatisfeitas. Dessa forma, os movimentos sociais contribuem decisivamente para engendrar novos direitos e para alcançar a efetividades de antigos direitos (WOLKMER, 2001, p. 119-168). Com fundamento nessas considerações seria possível, por exemplo, examinar como os movimentos sociais urbanos estão construindo o direito à cidade nos níveis local, nacional e global.

O modelo de pluralismo jurídico comunitário-participativo proposto por Wolkmer estabelece parâmetros teóricos que permitem avaliar os sistemas jurídicos pluralisticamente fundados. $\mathrm{O}$ autor mostra que existem 
práticas de pluralismo jurídico conservadoras e progressistas e centra sua atenção nos critérios de legitimidade que permitem diferenciar umas das outras. São dois os conjuntos de critérios de avaliação da legitimidade das práticas de pluralismo jurídico sugeridos por Wolkmer: a) os fundamentos de efetividade material; e b) os fundamentos de efetividade formal. O primeiro pilar de critérios contempla: a.1) a emergência de novos sujeitos coletivos; e a.2) a satisfação das necessidades humanas fundamentais. O segundo pilar de critérios leva em consideração três fatores: b.1) a reordenação da esfera pública mediante uma política democrático-comunitária descentralizadora e participativa; b.2) o desenvolvimento da ética concreta da alteridade; e c.3) a construção de processos para uma racionalidade emancipatória (Quadro 2) (2001, p. 231-232).

\begin{tabular}{|c|c|}
\hline \multicolumn{2}{|c|}{ CRITÉRIOS DE LEGITIMIDADE: } \\
\hline (a) fundamentos de efetividade material: & (b) fundamentos de efetividade formal: \\
\hline $\begin{array}{l}\text { (a.1) emergência de novos sujeitos coletivos } \\
\text { Identidades coletivas conscientes, mais ou menos } \\
\text { autônomas, classistas e inter-classistas, com capa- } \\
\text { cidade de auto-organização e autodeterminação, } \\
\text { interligadas por formas de experiências vividas, } \\
\text { interesses e valores comuns, compartilhando con- } \\
\text { flitos e lutas cotidianas que expressam privações e } \\
\text { necessidades por direitos. }\end{array}$ & $\begin{array}{l}\text { (b.1) a reordenação da esfera pública } \\
\text { Implementação de uma política demo- } \\
\text { crática que direcione e ao mesmo tempo } \\
\text { reproduza uma esfera pública comunitária, } \\
\text { descentralizada e participativa. }\end{array}$ \\
\hline \multirow[t]{2}{*}{$\begin{array}{l}\text { (a.2) satisfação das necessidades humanas funda- } \\
\text { mentais } \\
\text { Sentimento, intenção ou desejo consciente coleti- } \\
\text { vo, que envolve exigências valorativas, motivando } \\
\text { o comportamento humano para aquisição de bens } \\
\text { materiais e imateriais considerados indispensáveis } \\
\text { e essenciais à vida cotidiana. }\end{array}$} & $\begin{array}{l}\text { (b.2) ética concreta da alteridade } \\
\text { Formulação de valores éticos emancipa- } \\
\text { tórios, que emergem das próprias lutas, } \\
\text { conflitos, interesses e necessidades de su- } \\
\text { jeitos individuais e coletivos insurgentes, } \\
\text { refletindo uma práxis concreta comprome- } \\
\text { tida com a dignidade do outro. }\end{array}$ \\
\hline & $\begin{array}{l}\text { (b.3) racionalidade emancipatória } \\
\text { Exigência de uma racionalidade prove- } \\
\text { niente da vida concreta, comprometida } \\
\text { com o processo de desmistificação e cons- } \\
\text { cientização, fundada em uma estratégia de } \\
\text { pedagogia libertadora. }\end{array}$ \\
\hline
\end{tabular}

Quadro 2: Critérios de legitimidade

Fonte: Adaptado de Wolkmer (2001)

Examinado as relações entre os pilares, o autor explica que 
a estratégia de "efetividade material" compreende, de um lado, os sujeitos coletivos de juridicidade internalizados prioritariamente nos novos movimentos sociais; de outro, a estrutura da satisfação das necessidades humanas que passa a ser a justificativa, a razão de ser, o que legitima o agir dos novos atores sociais. Por sua vez, a estratégia de "efetividade formal" integraliza os procedimentos na "prática" (do agir, da ação) e na "teoria" (do conhecimento, do pensamento). O procedimento da "prática" desdobra-se em "ação coletiva" (implica reordenar a sociedade para uma política de democracia descentralizadora e participativa) e em "ação individual" (desenvolvimento pedagógico de um sistema concreto de valores éticos da solidariedade, configurado no que se poderia designar como "ética da alteridade"). Já o procedimento "teórico" está direcionado a construir processos de racionalidade comprometidos com a autonomia e a emancipação da essência humana. (WOLKMER, 2001, p. 234-235).

O arranjo de propriedade em relação a um dado espaço público da cidade poderia ser avaliado de acordo com o modelo de pluralismo jurídico comunitário-participativo proposto por Wolkmer. O arranjo de propriedade será tanto mais legítimo quanto em maior grau se aproximar dos fundamentos de efetividade material e formal explicitados. Em outros termos, quanto mais nele se fizer presente a emergência de novos sujeitos coletivos - como associações de moradores de bairro e de usuários - e quanto mais estiver voltado à satisfação de necessidades humanas fundamentais - como a de se encontrar com o diferente, de interagir com o estranho, de enriquecer-se reciprocamente vivendo com o outro -, maior a sua efetividade material enquanto experiência justa de pluralidade; quanto mais ele estiver permeado pela reordenação da esfera pública - pela participação direta da comunidade na construção do orçamento da cidade, por exemplo -, pela ética concreta da alteridade - respeito à dignidade do outro que leva uma vida cotidiana distinta - e pela racionalidade emancipatória - interação fundada na troca de saberes, no convencimento argumentativo -, mais ampla a sua efetividade formal enquanto práxis que almeja a construção e realização do direito ao espaço público e, em última instância, do direito à cidade. 
Os critérios de legitimidade delineados no modelo de pluralismo jurídico comunitário-participativo parecem capazes de iluminar alguns célebres debates contemporâneos acerca dos espaços públicos urbanos. É o caso daquele travado entre Mitchell e Ellickson em relação à proposta do último de estabelecer o zoneamento comunitário dos espaços públicos das cidades nos EUA.

Em seus estudos, Ellickson argumenta que os controles informais da ordem social são frequentemente mais efetivos para prevenir e resolver conflitos que aqueles legais (ELLICKSON, 1991). Adepto de valores liberais, o autor desconfia do Estado tanto na escala nacional quanto na escala local e, estendendo seu argumento à gestão das cidades, sugere que os proprietários privados são em maior medida capazes de fazer valer a preservação de qualidades urbanas do que as burocracias estatais. Partindo dessa premissa, Ellickson recomenda mudanças na gestão dos espaços públicos urbanos nos EUA. A regulação desses espaços não necessariamente deveria se vincular ao previsto nas normas constitucionais federais. Diferentemente disso, propõe o autor, ela deveria variar de acordo com as circunstâncias das distintas realidades sociais e, portanto, ser diretamente estabelecida pelas correspondentes comunidades por meio de normas instituídas pelas distintas vizinhanças, ou ao menos por normas específicas para cada vizinhança fixadas pelas municipalidades (ELLICKSON, 1996).

Ellickson desenvolve em seguida seu argumento em direção a uma detalhada proposta de zoneamento do espaço público urbano (ELLICKSON, 1996). De acordo com o autor, ao invés de ilegalizar conjuntamente os comportamentos indesejados (regimes regulatórios gerais e idênticos para todos os espaços públicos urbanos), as cidades deveriam estabelecer normas diferentes para lugares distintos: por exemplo, um conjunto de zonas hipotéticas de cor vermelha, amarela e verde, respectivamente indicando que um pedestre ordinário deveria ficar muito atento, preocupar-se em razoável medida ou acreditar na promessa de que está em um lugar relativamente seguro em relação a comportamentos potencialmente perturbadores. A razão para distinguir as zonas seria supostamente o fato de que o grau de dano causado por algumas condutas muda ao longo do perímetro urbano na medida em que se defronta com as sensibilidades de distintas comunidades urbanas. Ellickson pensa que o tipo de zona a ser 
adotado e o respectivo padrão de comportamento deveriam ser informalmente definidos por cada comunidade urbana e efetivados com a ajuda de agentes da polícia considerados confiáveis (ELLICKSON, 1996). Em resumo, o que Ellickson está sugerindo pode ser interpretado como uma forma liberal-conservadora de pluralismo jurídico, a despeito de o autor preferir falar em práticas informais de manutenção da ordem ou normas sociais.

Mitchell nota esse caráter conservador e sublinha dois pontos cruciais: Ellickson não define explicitamente o que significa e o que delimita uma comunidade urbana e tampouco responde a pergunta acerca de como determinar os padrões comunitários informais de comportamento. Sua noção de comunidade aparentemente não inclui, por exemplo, as pessoas em situação de rua, já que em princípio consiste em uma comunidade de detentores de propriedade privada na cidade (MITCHELL, 2003, p. 217218). "Nós devemos sempre estar conscientes de quem se beneficia da ordem social e do consenso e de quem não se beneficia, de quais interesses são servidos e quais não são", Mitchell adverte (2003, p. 219, tradução nossa). Mas há um problema na crítica de Mitchell. O autor parece duvidar da existência de normas jurídicas informais. Uma abordagem pluralista do direito provavelmente conduziria Mitchell a desenvolver melhor seu incipiente argumento sinalizando que "se elas de fato existem, [...] [as normas comunitárias] são o resultado de luta social séria e conjunta" (2003, p. 219, tradução nossa). Precisamente por essa razão, tais formas de direito governando o espaço deveriam ser consideradas modos de regulação que podem ser tanto opressivos quando emancipatórios e, portanto, também sujeitos à luta social.

Aplicar ao debate o modelo de pluralismo jurídico comunitário-participativo fortaleceria a objeção de Mitchell a Ellickson, sem que fosse preciso, ao mesmo tempo, negar que existem normas jurídicas não estatais e desconsiderá-las enquanto uma esfera de luta social. Um exercício de avaliação do arranjo de propriedade proposto por Ellickson deixaria patente que este não cumpre com os critérios de efetividade material e formal e, portanto, tende a reforçar a violação ao invés da efetivação do direito à cidade. Por exemplo, as comunidades de vizinhos enquanto unidades sociais das quais partiriam normas informais sobre os padrões de 
comportamento, se de um lado parecem contemplar o critério correspondente à emergência de novos sujeitos coletivos, por outro falham em observar o critério referente à ética concreta da alteridade na medida em que negam aos moradores de rua a possibilidade de integrar o processo de deliberação comunitário.

\section{Conclusão}

Ao desafiar a noção de estatalidade do direito, a teoria do pluralismo jurídico oferece uma visão mais ampla e dinâmica das normas que se vinculam ao processo de produção social dos espaços públicos urbanos. O pluralismo jurídico revela-se na percepção da prática espacial conflituosa do dia-a-dia da cidade, que molda e é moldada na luta social entre a hegemonia das representações do espaço concebidas pelo capital e a resistência dos espaços de representação vivenciados pelos movimentos sociais urbanos. Pluralidade de formas normativas que se faz presente no desenrolar da construção do direito à cidade, o qual sintetiza a denúncia do direito urbano que promove o desencontro com o outro e a opressão e, ao mesmo tempo, o anúncio da possibilidade de sua superação pelo direito urbano que encoraja o encontro com o outro e a libertação.

\section{Referências}

AZUELA, Antonio. La ciudad, la propiedad privada y el derecho. 2. ed. México: El Colegio de México, 1999.

BENDA-BECKMANN, Franz von. Who's afraid of legal pluralism? Journal of Legal Pluralism, v. 47, p. 37-83, 2002.

; BENDA-BECKMANN, Keebet von; WIBER, Melanie.

The properties of property. In:___ (Ed.). Changing properties of property. New York, Oxford: Berghan Books, 2006. p. 01-39.

ELLICKSON, Robert. Controlling chronic misconduct in city spaces: of panhandlers, skid rows, and public-space zoning. The Yale Law Journal, v. 105, n. 5, p. 1165-1248, 1996. 
. Order without law: how neighbors settle disputes. Cambridge: Harvard University Press, 1991.

FRIEDMAN, Lawrence. Coming of age: law and society enters an exclusive club. Annual Review of Law and Social Science, v. 1, p. 1-16, 2005.

GILISSEN, John (Ed.). Le pluralisme juridique. Bruxelles: Éditions de l'Universitè de Bruxelles, 1972.

HOOKER, M. B. Legal pluralism: an introduction to colonial and neocolonial laws. Oxford: Clarendon Press, 1975.

JUNQUEIRA, Eliane; RODRIGUES, José Augusto de Souza. A volta do parafuso: cidadania e violência. In: SANTOS JR., Belisário dos (Ed.). Direitos humanos: um debate necessário. São Paulo: Brasiliense, 1988. p. 120-140.

KONZEN, Lucas Pizzolatto. A Ciência Jurídica na Encruzilhada: Uma Reflexão Sobre Paradigmas. Revista Sociologia Jurídica, n. 10, 2010.

MENSKI, Werner. Comparative law in a global context: the legal systems of Asia and Africa. 2. ed. Cambridge: Cambridge University Press, 2006.

MITCHELL, Don. The right to the city: social justice and the fight for public space. New York: The Guilford Press, 2003.

MOORE, Sally Falk. Law and social change: the semi-autonomous social field as an appropriate subject of study. Law \& Society Review, v. 7, n. 1, p. 719-746, 1972.

SANTOS, Boaventura de Sousa. A crítica da razão indolente: contra o desperdício da experiência. 3. ed. São Paulo: Cortez, 2001.

. Toward a new common sense: law, science and politics in the paradigmatic transition. New York: Routledge, 1995.

. O discurso e o poder: ensaio sobre a sociologia da retórica jurídica. Porto Alegre: Sergio Antonio Fabris, 1988a. 
. Sociologia na primeira pessoa: fazendo pesquisa nas favelas do Rio do Janeiro. Revista da Ordem dos Advogados do Brasil, Brasília, n. 49, ano XX, v. 19, p. 39-79, 1988b.

. Os conflitos urbanos no Recife: o caso do "Skylab". Revista Crítica de Ciências Sociais, n. 11, p. 09-59, 1983.

. O Estado, o poder e a questão urbana. Revista Crítica de Ciências Sociais, n. 9, p. 09-86, 1982.

. Notas sobre a história jurídico-social de Pasárgada. In: SOUTO, Cláudio; FALCÃO, Joaquim (Ed.). Sociologia e direito: textos básicos de sociologia jurídica. São Paulo: Pioneira, 1980. p. 109-117.

. The law of the oppressed: the construction and reproduction of legality in Pasargada. Law \& Society Review, v. 12, p. 5-126, 1977.

WOLKMER, Antonio Carlos. Pluralismo jurídico: fundamentos de uma nova cultura no direito. 3. ed. São Paulo: Alfa-Ômega, 2001.

Recebido em: 02/10/2010

Revisado em: 17/10/2010

Aprovado em: 01/11/2010 